Florida International University

FIU Digital Commons

FIU Electronic Theses and Dissertations

University Graduate School

$3-25-2010$

\title{
The Effects of Classroom Environmental Quality on the Early Literacy Outcomes of a Regionally Heterogeneous Population of Latino Children
}

Maria M. Marin

Florida International University, marinm82@gmail.com

DOI: $10.25148 /$ etd.FI10041634

Follow this and additional works at: https://digitalcommons.fiu.edu/etd

Part of the Other Education Commons

\section{Recommended Citation}

Marin, Maria M., "The Effects of Classroom Environmental Quality on the Early Literacy Outcomes of a Regionally Heterogeneous Population of Latino Children" (2010). FIU Electronic Theses and Dissertations. 162.

https://digitalcommons.fiu.edu/etd/162

This work is brought to you for free and open access by the University Graduate School at FIU Digital Commons. It has been accepted for inclusion in FIU Electronic Theses and Dissertations by an authorized administrator of FIU Digital Commons. For more information, please contact dcc@fiu.edu. 


\section{FLORIDA INTERNATIONAL UNIVERSITY}

Miami, Florida

THE EFFECTS OF CLASSROOM ENVIRONMENTAL QUALITY ON THE EARLY LITERACY OUTCOMES OF A REGIONALLY HETEROGENEOUS POPULATION OF LATINO CHILDREN

A thesis submitted in partial fulfillment of the requirements for the degree of MASTER OF SCIENCE in EARLY CHILDHOOD EDUCATION

by

María Mercedes Marín 


\section{To: Interim Dean Marie McDemmond College of Education}

This thesis, written by María Mercedes Marín, and entitled The Effects of Classroom Environmental Quality on the Early Literacy Outcomes of a Regionally Heterogeneous Population of Latino Children, having been approved in respect to style and intellectual content, is referred to you for judgment.

We have read this thesis and recommend that it be approved.

Louis Manfra

$\begin{array}{r}\hline \text { Louis Manfra } \\ \hline \text { Charles Bleiker } \\ \hline \text { Laura Dinehart, Major Professor }\end{array}$

Date of Defense: March 25, 2010

The thesis of María Mercedes Marín is approved.

\begin{tabular}{r}
$\begin{array}{r}\text { Interim Dean Marie McDemmond } \\
\text { College of Education }\end{array}$ \\
\hline Interim Dean Kevin O'Shea \\
University Graduate School
\end{tabular}

Florida International University, 2010 
C Copyright 2010 by María Mercedes Marín

All rights reserved. 


\section{DEDICATION}

I dedicate this thesis to my family. With risk and hope, they crossed that invisible border, which without it, this work would have been impossible. 


\begin{abstract}
OF THE THESIS
THE EFFECTS OF CLASSROOM ENVIRONMENTAL QUALITY ON THE EARLY

LITERACY OUTCOMES OF A REGIONALLY HETEROGENEOUS POPULATION OF

LATINO CHILDREN
\end{abstract}

by

María Mercedes Marín

Florida International University, 2010

Miami, Florida

Professor Laura Dinehart, Major Professor

The purpose of this study was to examine the relation between classroom environmental quality and early literacy outcomes amongst a sample of Latino children from various Latin-American countries. Participants included 116 preschoolers that attended various childcare centers in Southeast Florida. Participant's literacy knowledge was assessed using the Test of Preschool Early Literacy. Classrooms were assessed on environmental quality using the Early Childhood Environmental Rating Scale-Revised.

A regression analysis revealed that classroom environmental quality did not account for Latino children's early literacy outcomes. However, a multiple regression analysis was significant $\left(R^{2}=.15, F(5,115)=3.86, p<.05\right)$ indicating that quality has a varying impact on children's early literacy skills based on children's region of origin.

Findings suggest that high classroom environmental quality does not necessarily mean better literacy development for Latino children. Additionally, Latino children should not be viewed as a homogeneous group, particularly in relation to their development of literacy skills in English. 


\section{TABLE OF CONTENTS}

CHAPTER

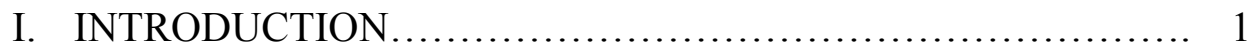

II. LITERATURE REVIEW ....................................... 8

Theoretical Framework $\quad 8$

Quality Learning Environments 11

Latinos in Early Childhood Research 19

Current Study 25

III. METHODOLOGY......................................... 28

Participants $\quad 28$

Procedures $\quad 29$

Measures 31

IV. RESULTS..................................................... 34

Research Question 1

Research Question 2

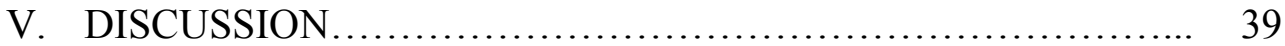

Implications for Future Research 41

Limitations and Future Research Directions $\quad 42$

Conclusion $\quad 43$

LIST OF REFERENCES......................................... 45 


\section{CHAPTER I}

\section{Introduction}

\section{Purpose of the Study}

The present study has two main purposes. The first is to investigate the relationship between early classroom environmental quality and the early literacy skills of a sample of at-risk, low-income Latino children who participated in the Early Reading First-Learning Educational Approaches for Reading Now (ERF-LEARN) program. The second purpose is to examine whether the relationship between classroom environmental quality and early literacy outcomes varies as a function of child's region of origin.

\section{Derivation of Research Questions and Hypotheses}

Early literacy programs, like those that have been implemented in the federally funded Early Reading First programs, have promoted "research based" curricula as the cure-all for low literacy levels in children with multiple risk factors. These programs follow a classical learning theory model of development, where ecological factors (family background, culture, and language) take a back seat to biological learning processes. The

current study, developed from an ecological perspective, suggests that the school environment should interact with the child in unique ways depending on how it affects the overall ecology of the school and culture.

In order to test this hypothesis, two variables, classroom environmental quality, as measured by the Early Childhood Environment Rating Scale-Revised (ECERS-R; Harms, Clifford, \& Cryer, 2005), and region of origin, as measured by the Test of Preschool Early Literacy (TOPEL; Lonigan, Wagner, Torgesen, \& Rashotte, 2007), will be explored. These variables will be studied to determine how they predict performance 
amongst a diverse group of at-risk Latino children on a standardized test of early literacy. Latino children are of particular interest because while they are similar in linguistic background (i.e., their parents first language is Spanish and their children are learning literacy in English), they differ in their cultural background depending on their home country or region of origin. This provides a unique opportunity to study how subtle variations in culture (high-level ecological influences) interact with classroom environments (low-level ecological influences) while holding linguistic background constant. Further, this provides a framework to explore if early literacy instruction should be the same for all at-risk children, regardless of family backgrounds, cultures, and community.

\section{Research Questions and Hypotheses}

The overarching research question that guided this research study was: Does classroom environmental quality have an effect on early literacy outcomes in low-income Latino children based on their region of origin? This question was broken down into two different empirical questions along with hypotheses:

1. Does classroom environmental quality, as measured by the ECERS-R, predict early literacy as measured by the TOPEL?

Children who participated in this study were part of the nationwide Early Reading First (ERF) Program, which was created in 2001 by the No Child Left Behind Act. The main goal of the ERF Program was to prepare and give students the right tools in literacy so they can have a successful transition into kindergarten. This included improving preschool classroom environments, teacher practices, and instructional content (U.S. Department of Education, National Center for Education Statistics, 2007). Research has 
provided evidence that high quality childcare centers that provide developmentally appropriate practices as well as well-trained caregivers have positive effects on children's developmental outcomes (e.g. Cryer, 1999, Vernon-Feagans, Scheffner Hammer, Miccio, \& Manlove, 2003, National Institute of Child Health and Human Development [NICHD] Early Child Care Research \& Duncan, 2003, Burchinal, Roberts, Riggins, Zeisel, Neebe, \& Bryant, 2000; Takanishi, 2004). This study empirically examines the effectiveness of early classroom environmental quality, measured by the Early Childhood Environment Rating Scale-Revised (ECERS-R; Harms et al., 2005), as it relates to early literacy outcomes as measured by the Test of Preschool Early Literacy (TOPEL; Lonigan et al., 2007). It is hypothesized that quality of the early classroom environment, as measured by the ECERS-R, will be a significant predictor of students' scores of the TOPEL at the end of the academic year.

2. Does the relation between classroom environmental quality and outcomes in early literacy vary as a function of region of origin in Latino children?

The current study will also examine whether region of origin significantly moderates the relationship between quality of the classroom environment and early literacy outcomes. Region of origin was determined through children's primary caregivers who filled out a demographic survey during the middle of the school year. Region of origin was divided into three categories, which include: Mexico and Central America, South America, and the Latino Caribbean. It is often the case that students who are described as Latino are lumped into one group, despite the fact that Latino refers to distinctly different regions (Flores, Cicchetti, \& Rogosch, 2005). Given that Latino children are at risk for school failure (Vernon-Feagans et al., 2003), it is important to understand how the quality of the 
classroom environment in pre-kindergarten predicts early literacy outcomes as a function of region of origin. Research suggests that children from countries other than the United States may have different modes of literacy that are practiced at home. As such, what is deemed as high "quality" for white middle class children may not be the case for lowincome Latino students. It is hypothesized that an interaction effect will exist between early classroom environmental quality and early literacy outcomes as a function of region of origin, such that children from the Latino Caribbean will fare better than the other groups due to the socioeconomic status of the region and the social support provided to them in Southeast Florida. Children under 18 years old represent $29.8 \%$ and $24 \%$ of Mexicans and Central Americans who are under the poverty level compared to the $14 \%$ of Cuba and $13.7 \%$ of other Hispanics that are below the poverty level (U.S. Census, 2008).

\section{Conceptual Model}

Research that has focused on classroom environmental quality and its impact on early literacy outcomes has provided evidence that childcare centers rated as high quality often lead to better early literacy outcomes for children attending these types of centers (Burchinal et al., 2000; Cryer, 1999). A conceptual model has been developed for question one based on the hypothesis and current literature (Figure 1).

\begin{tabular}{|c|c|}
\hline $\begin{array}{c}\text { Classroom } \\
\text { Environmental } \\
\text { Quality }\end{array}$ & $\begin{array}{l}\text { Early Literacy } \\
\text { Outcomes }\end{array}$ \\
\hline
\end{tabular}

Figure 1. Direct relationship of quality and literacy in a path diagram.

In order to provide these children with high quality classrooms that will cultivate their early literacy skills, researchers need to have a better understanding of the 
demographics and cultural contexts that surround children. This means, understanding how the development of children's emergent literacy skills may differ from region to region, and how "white middle-class standards" of quality may not be culturally-sensitive or even applicable to these diverse populations (Brophy \& Statham, 1994; García Coll, 1990; García Coll, Lamberty, Jenkins, McAdoo, Crnic, Waskik, \& Vázquez García, 1996; Johnson, Jaeger, Randolph, Cauce, Ward, \& NICHD Early Child Care Research Network, 2003; Lamb, 1998). Based on the current research, a multiplicative model was created through model 1 showing the moderated effect region of origin might have on early literacy outcomes based on classroom environmental quality (Figure 2).

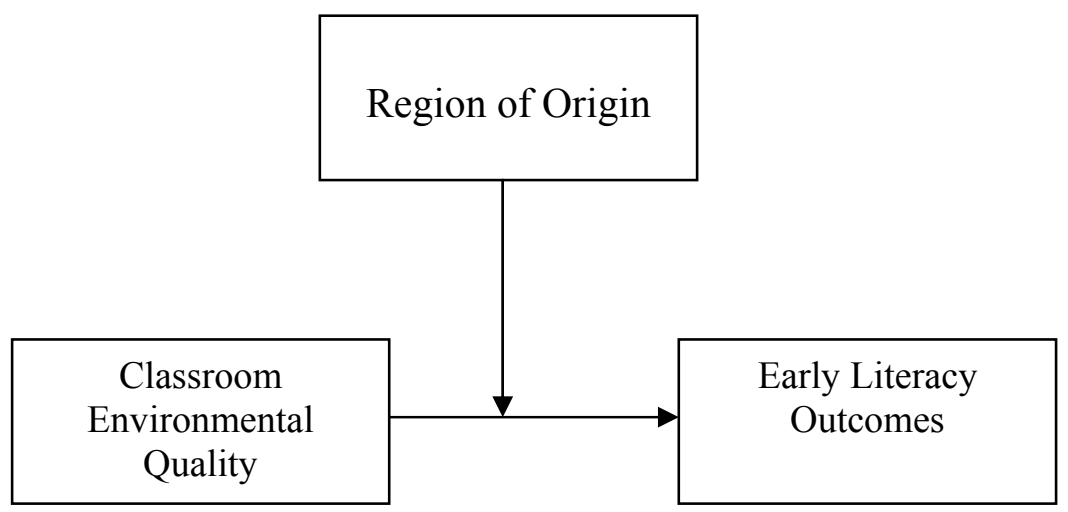

Figure 2. Moderated relationship of Classroom Environmental Quality and Literacy Outcomes through Region of Origin in a path diagram.

\section{Rationale}

According to the U.S. Census Bureau, the Latino population is expected to triple over the next half century. Therefore, it is important to understand factors that tend to influence the early learning of this population. Environmental factors have long contributed to not only children's learning but also to their cognitive development (Vernon-Feagans et al., 2003). In recent years, researchers have set out to define quality 
and have generalized their definition of high quality environments to all children.

Literacy programs often impede norms that are not congruent with Latino children's style of learning and as a result Latino children have the added burden of negotiating different sets of literacy rules not only at school, but at home as well (Vernon-Feagans et al., 2003). It is important to understand if the definition of high quality learning environment, as measured by standard tools, is extended to this group, and how it affects the acquisition of early literacy skills in Latino children.

\section{Delimitations}

The participants in this study were limited to preschool children attending four different pre-school centers who were randomly chosen to participate in the ERFLEARN program. The sample size was limited to parents who filled out the demographic survey, thus examining diversity was restricted to the parent who filled out the survey limiting the information of where the child's father or mother descended from giving who filled out the information.

\section{Overview of Chapters}

In this chapter, the researcher explains the purpose of the study, derivation of research questions and hypotheses, as well as the research questions and hypotheses followed by a conceptual model of each. In addition, chapter one gives the rationale, assumptions, delimitations, and overview of chapters for the study. For chapter two, a review of the literature based on the research questions are explored. In chapter three, a comprehensive, detailed description of the conceptual model and methods is given to address the research questions pertinent to the study followed by the results in chapter four. For the final chapter, a summary of the study with an overview and evaluation of 
the findings will be provided. A discussion on the results and limitations of the study will also be discussed as well as its implications in early childcare research and policy practices. 


\section{CHAPTER II}

\section{Literature Review}

Current estimates indicate that more than 800,000 children across the nation are enrolled in preschool programs (Barnett, Hustedt, Robin, \& Schulman, 2005). In 2005, the National Center for Education Statistics (NCES) reported that $57 \%$ of children in the United States between the ages of three and five were attending center-based programs. Of the $57 \%$ of children enrolled, $69 \%$ were between the ages four and five. State and federal government agencies continue to fund early childhood programs with the intention of assuring that all children enter school ready to learn. Although enrollment into these programs continues to grow, the progress to diminish the achievement gap between White and Latino students continues to be slow (Norman, Ault, Bentz, \& Meskimen, 2001). As such, two issues have become important to the current early childhood education literature, (1) quality of the early learning environment and (2) the diversity of children in the early childhood classroom. The first section of this review of literature describes a brief theoretical framework, followed by a clear examination of the research on the quality of the childcare learning environment including how quality is currently defined and regularly assessed. The second section of this review covers the literature concerning the Latino population in the early childhood research. The final section will provide a brief description of the context of the current study, which when combined with the other sections will provide the necessary background information for the current research.

\section{Theoretical Framework}

Children's development is strongly influenced by many factors, including the 
environment in which they are reared. Indeed, research has shown that a child's environment is a strong contributor to their social, emotional, cognitive, and academic development (Han, 2006; Dickinson \& Sprague, 2003). Two important points that have been established within current developmental theories are: 1) to understand development, we must view it from the molecular to the cultural, paying attention to all the levels involved in a dynamic developing system and their interactions and 2) to understand development, we must view it as an embedded process that reveals itself in many different time frames, ranging from milliseconds to years (Thelen \& Smith, 1998). In other words, development occurs in the connection between a person and the immediate surroundings. For a child, this includes the connections with parents, teachers, and culture (Bronfenbrenner \& Evans, 2000).

Current research on early childhood education has explored both home and childcare environments through an ecological approach (Burchinal et al., 2000). Developmental theorists (e.g. Piaget, Dewey, and Malaguzzi) argue that children actively explore their environments creating solutions to problems they encounter within their surroundings (Roskos \& Neuman, 2003). Interactions with the immediate environment represent proximal processes. These process, are bidirectional in that the process involves a "transfer of energy between the developing human being and the persons, objects, and symbols in the immediate environment" (Bronfenbrenner \& Evans, 2000, p. 118). Given that stimulating environments in the early years are correlated to the neural organization of the brain (Vernon-Feagans et al., 2003), children who attend childcare centers, especially preschool-aged children, require meaningful interactions with their parents and other caregivers to foster early academic development (NICHD Early Child 
Care Research Network \& Duncan, 2003). The childcare environment has a crucial role in how and what a child learns, holding a valuable place in a child's education and emphasizing the importance of the childcare quality (Roskos \& Neuman, 2003).

While the home is generally considered the primary environment in which children are raised, ecological models (e.g., Bronfenbrenner \& Morris, 1998) emphasize that a child's development is also influenced by experiences outside the home, such as a childcare center (Han, 2006). The extent to which the early experiences are valuable depends, at least in part, on the environmental quality of the childcare (Burchinal et al., 2000; Dickinson \& Sprague, 2003; Vernon-Feagans et al., 2003). In a childcare center, children engage with their environment while acquiring different "intellectual tools" to help them prosper in circumstances they may deem challenging. This allows them to engage in meaningful thought and action (Roskos \& Neuman, 2003). Ecological models also suggest that the interaction between the home environment and other environments (e.g., childcare center) also strongly influence children's development. The current study focuses on the interactions between these systems, namely the extent to which the quality of the classroom environment significantly influences children's language and literacy development in a population of Latino preschoolers.

Emergent literacy, defined as the developmental skills that precede reading, has been shown to be a critical predictor of future reading and academic progress. The last decade has seen tremendous growth in the importance of emergent literacy skills. This includes phonological awareness, alphabet knowledge, print awareness, and vocabulary. Federal agencies have placed a significant emphasis on early reading with the passing of 
No Child Left Behind and the grants associated with the bill. Children that enter school without these skills are often considered at risk for academic failure.

Language and literacy are important factors in children's early childhood education since they have been shown to have significant implications for later in life (Whitehurst \& Lonigan, 2003). In today's society, a child does not have the luxury to be illiterate. Being able to read well helps the child to gain more knowledge in other areas where as children who do not read as much lag behind their peers and miss strategies to develop good reading comprehension strategies (Whitehurst \& Lonigan, 2003). To become successful in school and for the hopes of a successful career, a child must be able to properly communicate and understand what is being taught to them despite their language, culture, or race (Vernon-Feagans et al., 2003; Proctor, Carlo, August \& Snow, 2005). Having a command of oral language has been shown to be linked to reading comprehension outcomes as well along monolingual students, which just emphasizes the importance of vocabulary knowledge for English language learners (Procter et al., 2005). Not only is acquiring vocabulary important, literacy also helps bring awareness to metalinguistic, speech, and formal logical thought to name a few (Whitehurst \& Lonigan, 2003). It is therefore, important for children from different linguistic and cultural backgrounds to acquire the correct tools in order to be successful in school.

\section{Quality Learning Environments}

The spark of interest on the effects of the environment on development and early achievement comes from a variety of different entities (NICHD Early Child Care Research Network \& Duncan, 2003). Parents, who work and have been informed about the importance of early learning, deserve to place their children in a quality early 
learning center that offers their children the best opportunity to enhance their child's development. Similarly, early childhood teachers and professionals, national government agencies, and society as a whole, have a stake in quality education. Generally, preschool programs have been shown to be important in the early developmental and academic outcome of young children. Children who attend a school or center-based preschool before entering kindergarten perform better on measures of reading and mathematics upon entering kindergarten than those who do not attend preschool programs (Magnuson, Meyers, Ruhm, \& Waldfogel, 2004). The rise of women in the workforce (Dickinson \& Sprague, 2003) has resulted in an increasing need for researchers and policy makers to improve the quality of childcare to enhance the early development of all children. Perhaps, more importantly, these programs stand to enhance the developmental outcome of children who otherwise would be at risk for poor developmental outcomes.

Researchers agree that "high-quality care," is critical in influencing the development of children who attend preschool (Vandell \& Wolfe, 2000; VernonFeagans, Hurley, Yont, Wamboldt, \& Kolak, 2007; Cryer, 1999; Takanishi, 2004; NICHD Early Child Care Research Network \& Duncan, 2003). The NICHD Early Child Care Research Network and Duncan (2003) recently examined the causal impact of childcare quality on children's cognitive and academic achievement. Four focal variables were closely studied, including the type of care the child received, the child's home, the child, and the child's family. The researchers recruited 1,327 mothers from ten different locations in the United States, which included California, Massachusetts, and North Carolina. A level model analysis indicated a linear relationship between 
childcare quality, as measured by the Observational Record of the Caregiving Environment (ORCE) and child cognitive and academic outcomes. Their most significant relations were found in children three and four years of age for which the amount of time spent in childcare center was positively related with outcomes in both academic and cognitive achievements. Their most inclusive model suggested that increase in high quality care was associated with a 2.6-point increase in cognition, while controlling for critical variables such as child temperament, maternal personality, and maternal separation anxiety. The research also suggests that quality of childcare was important in enhancing the language development of children who come from impoverished families (NICHD Early Child Care Research Network \& Duncan, 2003).

Similarly, Burchinal and her colleagues (2000) examined the extent to which quality of childcare was associated with language, literacy, and communication outcomes in the first three years of life. Measures for quality included the Infant/Toddler Environment Rating Scale (ITERS) and the Early Childhood Environment Rating Scale (ECERS). Results indicated there was a significant relationship between quality of childcare and early language and literacy abilities in the first three years of life even after controlling for family characteristics. As such, it appears that quality is important to providing a conducive environment for children to learn. In low-income populations, high quality childcare centers appear to have the ability to enhance the language and literacy development of children who come from underprivileged families (NICHD Early Child Care Research Network \& Duncan, 2003), ultimately serving as a protective factor for the population (Votruba-Drzal, Coley, \& Chase-Lansdale, 2004). In fact, the extent to which demographic and family characteristics predict later literacy outcomes appear to be 
dependent, at least in part, on the type and quality of childcare a child receives (NICHD Early Child Care Research Network \& Duncan, 2003).

Children's experiences in the classroom have been linked to their developmental outcomes (Cryer, 1999). Yet, defining childcare environmental quality is no easy task, as quality can be interpreted in many different ways (Dickinson \& Sprague, 2003; Lamb, 1998; Phillips \& Howes, 1987; Vandell \& Wolfe, 2000). Quality of care is broadly defined as an early learning environment that enhances positive development in young children (Dickinson \& Sprague, 2003). Poor quality may include centers that are insensitive to their students' culture, centers that produce poor student achievement, and centers that lack a scientifically based curriculum. All of these factors are thought to impede teaching and learning (Han, 2008). Although it seems that quality is an overwhelmingly powerful predictor of long-term outcome, much of the research on quality of care has modestly accounted for $5 \%$ of the variance on children's developmental outcomes (NICHD Early Child Care Research Network \& Duncan, 2003). Although a singular definition of quality, as it pertains to the early childhood classroom has not been established (Lamb, 1998; Phillips \& Howes, 1987, \& Vandell \& Wolfe, 2000), researchers have historically identified classroom quality across two broad concepts.: (1) the process quality of preschool classroom and (2) the structural quality of the preschool classroom (Vandell \& Wolfe, 2000; Cassidy, L. Hestenes, Hegde, S. Hestenes, \& Mims, 2005; Lamb, 1998; Mashburn et al., 2008; Phillips \& Howes, 1987). Process quality refers to actual experiences in a childcare setting such as a child's interaction with the caregivers and other children (Cryer, 1999). Stimulating activities, such as language stimulation, appropriate developmental practices, and safety measures 
have been found to have long-term impact between process quality and children's developmental outcomes (Vandell \& Wolfe, 2000; Vernon-Feagans et al., 2007; Cryer, 1999).

Researchers also identify classroom quality through structural quality, which has also been shown to have a positive impact on children's development. Structural quality in a learning environment refers to different stimuli that create processes that children actually experience throughout their environment (Cryer, 1999). These would include the quality of the childcare setting and its caregivers. Some examples of this include child-to-adult ratios, the number of children in each classroom, and the type of education and training the caregivers have received (Vandell \& Wolfe, 2000; Cryer, 1999). These are just some variables that make up structural quality in a classroom. Structural quality is said to be important to a child's development because classrooms that have low adultchild ratios have resulted in children demonstrating less hostile behaviors, and having a better grasp of the content being taught. Consequently, children are more able to participate in meaningful interactions with both their peers and teachers (Vandell \& Wolfe, 2000; Vernon-Feagans et al., 2007). However, structural quality can differ significantly both across and within states, as federal regulations do not exist and state policy can vary (Magnuson et al., 2004). Generally, research suggests that both structural and process variables are important to understanding the varying quality of childcare.

Takanishi (2004) reviewed several studies of early education programs and identified five common elements that have indicated high quality childcare. These include: 1) children with extended exposure of learning materials in the classroom, 2) 
group educational services in line with children's developmental characteristics, 3) teachers who have a bachelor's degree and are reasonably compensated, 4) small class sizes, and 5) parental involvement (Takanishi, 2004). These common elements resonate with both the structural and process qualities that researchers have stressed throughout the years (Cryer, 1999; Magnuson et al., 2004; Vandell \& Wolfe, 2000; Vernon-Feagans et al., 2007) and although there are different ways one can assess quality, one measure has been used most frequently to define and measure quality in childcare centers.

The Early Childhood Environment Rating Scale (ECERS; Harms \& Clifford, 1980 ) and the Early Childhood Environment Rating Scale-Revised (ECERS-R; Harms et al., 1998) have been the standard by which quality is assessed for more than 25 years. The ECERS-R has been a widely used measure due to its durability and comprehensiveness (Perlman, Zelman, \& Le, 2004). With research in early childhood education on the rise, there is now interest in implementing and evaluating the effectiveness of childcare centers. The ECERS-R allows teachers and directors to make the childcare environment accessible to all children. The ECERS-R measures multiple aspects of the childcare center environment that focuses on both the physical/structural quality of the environment and process-focused aspects, such as caregiver and child interactions (Perlman et al., 2004). An overall, single measure of quality of the environment is computed from an average of 36 items, in which a score of 1 indicates inadequate quality, a score of 3 indicates minimal quality, a score of 5 indicates good quality, and a score of 7 indicates excellent quality. The ECERS-R is the most widely used tool to identify, monitor, and provide guidance for quality programs.

The positive associations between the ECERS-R and various child outcome 
variables have been well-documented (Peisner-Feinberg \& Burchinal, 1997; PeisnerFeinberg et al., 2001). Yet, Mashburn and colleagues (2008) found that the ECERS-R was not a good measure of quality. In their study, they examined the development of academics, language, and social skills of four-year-old children who attended publicly supported pre-K programs and how this related to the quality within these programs. They used three methods to measure pre-K classroom quality that included: 1) how centers adhered to nine standards of quality recommended by the National Institute for Early Education Research (NIEER), 2) observations of overall quality, and 3) observations of teachers. Participants included 2,439 children of which 1,127 included children classified as Latino, making up only $17 \%$ of their sample. Mashburn and colleagues used two measures to test the overall quality of the center. The ECERS-R gave an overall quality while the Classroom Assessment Scoring System (CLASS) provided the quality of the teacher, which was broken down into emotional and instructional support. When testing for children's outcomes they used five different measures that included the Peabody Picture Vocabulary Test (PPVT), Oral and Written Language Scale (OWLS), rhyming, applied problems, and letter naming.

Their overall results indicated that the nine standards recommended by NIEER were not associated or related to children's outcomes. The ECERS-R also showed no significant associations with overall quality. The only thing that was positively linked with the ECERS-R was children's outcomes in expressive language. The only measure that was significantly correlated with children's outcomes was the CLASS, which measured child-teacher interactions (Mashburn et al., 2008). Upon closer examination, the authors report several limitations to the study, including the very small magnitudes of 
effects on children's development of academic, language, and social skills, even when significant. In fact, a half-point standard score increase was considered significant from pretest to posttest (Mashburn et al., 2008). Finally, Mashburn and his colleagues (2008) conducted the same set of analyses on a small proportion of children that were assessed in Spanish $(\mathrm{N}=283)$. The authors report that the results trended in the same direction, but were not statistically significant. These findings demonstrate the importance of understanding quality from a culturally sensitive lens that considers the educational and developmental needs of children who might come from culturally and linguistically diverse backgrounds.

Burchinal and Cryer (2003) considered the role of quality in ethnically and culturally diverse backgrounds. They focused on two groups that included African Americans, and English-speaking Latinos. Their study concluded that quality, as measured by common instruments, were reliable for diverse populations even if they were developed for white, middle-class children. Burchinal and Cryer's (2003) study, although inclusive of African American children, only focused on a very small number of Hispanic children. The first group of participants included 31 Hispanic children, while the second group examined 38-40 Hispanic children. This was insignificant compared to the 480 White children included in the sample. The study's structure made it dangerous to generalize the findings across all Latino children. In order to provide true high quality education and meet the needs of all students, a better understanding is needed of how children from different national and cultural backgrounds develop during their preschool years. 


\section{Latinos in Early Childhood Research}

Recent projections by the U.S. Census Bureau (2008) suggest that the nation's minority populations will soon be the majority. Currently, minorities comprise approximately one-third of the US population. Schools are likely to be affected even sooner, given that half of all children will be minorities by 2023 (U.S. Census Bureau, 2008). Current estimates from the National Center for Education Statistics indicated that in the 500 largest school districts, minority students already represent the majority; a total of 56 percent of the total population of students (Hoffman \& Sable, 2006). The Latino population, in particular, is growing and is estimated to triple over the next half century. In urban communities, minority children, including Latinos, disproportionately represent low-SES children (Proctor \& Dalaker, 2003).

In Southeast Florida, particularly in Miami-Dade County, the Latino population has grown exponentially within the last several decades (U.S. Census Bureau, 2008), a reason why research needs to be more inclusive (Johnson et al., 2003). Latinos comprise $62 \%$ of the population, making them the ethnic majority in Miami-Dade (U.S. Census Bureau, 2008). Only 18\% of Miami-Dade residents identify themselves as White nonHispanic, and 20\% identify themselves as Black (U.S. Census Bureau, 2008). Data from Miami Dade County Public Schools indicates that even in Miami-Dade County, a district representative of a Latino majority, Latinos are performing below their white counterparts by 34 points in reading and 26 points in mathematics on standardized state achievement tests (e.g. FCAT) by the time children reach third grade. In a recent policy report published by the Society of Research in Child Development, Garcia and Jensen (2009) emphasize that the United States should pay close attention on how Latino 
children are assessed. They claim there is a need in research to oversample Latino children in order to be able to compare them to other children from different countries of origin outside the United States, which can result in a more detailed picture of how they are performing (Garcia \& Jensen, 2009).

The word Latino is used when referring to children with Spanish speaking origins of Latin America, such as the Caribbean, Mexico, Central America, and South America (Flores et al., 2005). It cannot be overlooked that the word Latino is used as a homogenous label to describe over 40.4 million people, which make $14 \%$ of the population, the largest US ethnic minority group (Acevedo-Garcia, Soobader, \& Berkman, 2007), but yet all these people come from four distinct regions. The differences within cultures and subcultures give rise to variations of parenting techniques and how much parents are involved in their child's schooling. Super and Harkness (1986), do not examine t the bioecological, but the "ecocultural development niche" which is thought to include parents' expectations, beliefs of gender roles, religious and spiritual values, childrearing goals, and disciplinary practices (Meléndez, 2005). These differences and parents' experiences have distinct implications to their child's development (Meléndez, 2005). This is why the designation of "Latino" as a monolithic group is problematic for researchers who want to specify differences within the minority groups. In a metropolitan area such as Miami-Dade County, where the diversity of the Latino population defies easy categorization, this characterization may not be sufficient to explain differences in school outcomes because the term "Latino" does not capture the heterogeneity of this group. In Miami-Dade County, the total population equals 2.3 million, with Latinos making up $61 \%$ of the population, totaling 1.4 million people. A 
breakdown of Latinos in Miami-Dade County is as follows: Mexicans (3\%), Puerto Ricans (6\%), Cubans (53\%), Dominicans (3\%); Central Americans (14\%) which includes Costa Rica, Guatemala, Honduras, Nicaragua, Panama, El Salvador, and Other; South Americans (16\%) which include Argentina, Bolivia, Chile, Colombia, Ecuador, Paraguay, Peru, Uruguay, Venezuela, and Other; and Other Latinos (4\%) which includes the Spaniards, Spanish, Spanish American and all other Latinos (U.S. Census Bureau, 2008) .

Researchers and policy makers should refrain from viewing Latinos as a homogeneous group, as it leads to an overgeneralization of the different sub-groups that make up this whole. Of equal importance as a predictor may be country or region of origins, socio-economic status, and availability of quality early education experiences (Vernon-Feagans et al., 2003). Teacher's perceptions alone of children's race and class have shown to be related to student's performance as far as 9 years later (Han, 2008). The risk factors that face children from disadvantaged backgrounds can be silenced by attending schools with high quality care, however schools who have a majority population of low-income, minority children fail to give them a positive school environment, by having expecting poor school outcomes, having insufficient academic support and resources that limit students' school performance (Han, 2008).

According to Johnson et al. (2003), development in Latino children cannot be based on universal notions, instead it should be based on their specific ecological surroundings. For example, literature has suggested that positive school environments will mostly benefit the underprivileged Latin American populations, especially those 
children coming from Mexico (Han, 2008), which parallels the population of children residing in Southeast Florida.

Latinos in the United States are often at high risk for school failure (VernonFeagans et al., 2003; Johnson et al., 2003). These children typically perform 11-25\% below national averages on standardized tests and have difficulty learning to read in the early elementary grades. They start elementary school without the necessary foundation of pre-literacy skills that predict successful reading performance in the transitional years of kindergarten through third grade (Vernon-Feagans et al., 2003). These children often have early literacy experiences that are at odds with mainstream school literacy. Additionally, instructional models are often biased toward a more middle class conception of literacy. It favors children whose home life is more congruent with school objectives and it dismisses cultural idiosyncrasies, such as emergent literacy skills.

Latino children, in essence, may have the added burden of negotiating different sets of literacy rules in the home and school (Vernon-Feagans et al., 2003; Johnson et al., 2003). For example, not all minority students have the same access to books, as would a middle class family. Yet, some research indicates they are still being exposed to literacy. Since most parents of low socioeconomic level might have a hard time providing books for their children, this does not mean that they find ways in incorporating literacy into their children's daily life. In one study, they found that parents viewed children's worksheets sent from school as the proper way their children should learn how to read and write and were of more use to them as perhaps reading a book to their children (Vernon-Feagans et al., 2003). Other ways parents engage their children in literacy is through explanations, narratives, and pretend talk (Gillanders \& Jiménez, 2004). This is 
the traditional view of why so many Latino children across the United States begin school at a disadvantage and continue to struggle for years to come. In other words, children are void of any learning in their home because their parents do not read before their child goes to sleep, or provide different toys or tools to learn literacy.

Some research suggests that schools' approach to literacy may be discrepant to that of the Latino family. The Latino cultural model of literacy involves an enculturation process that begins in childhood and gradually is added onto by experiences and information that is transferred collectively to the child (Reese \& Gallimore, 2000). In Heath's 1982 study, he discovered that the bedtime stories that are so common in American culture are not common for Latino parents. Despite the fact that Latino parents may not participate in reading to their children during bedtime, Latino parents still monitor and assist their children with homework and by narrating folklore tales of their native country (Reese \& Gallimore, 2000). These are forms of extended discourse that includes explanations, narratives and pretend talk (Gillanders \& Jiménez, 2004). These forms of literacy, although unrecognized as literary practices, are a way to form a cultural identity (Gillanders \& Jiménez, 2004). In the Latino home, the cultural model of literacy encompasses repetition of symbol and sound relationships (Gillanders \& Jiménez, 2004; Reese \& Gallimore, 2000). Researchers should take into account the idiosyncrasies within the Latino community and understand that parents' cultural model of literacy can be adapted over time (Reese \& Gallimore, 2000).

Reese and Gallimore (2000) found that their participants did not recognize emergent literacy in their children. For example, when a kindergartner went home to show his mother he had another book she simply looked at him and nodded or when a 
child pretended to write, their parent, usually the mother, would respond with "[n]i siquiera sabes lo que estas rayando" (Reese \& Gallimore, 2000). This demonstrates how Latino parents do not understand what is considered literacy development within their children. Experiencing a discontinuity between child-rearing beliefs and practices at home and those at school may be more detrimental to developmental outcome than parental behavior alone. It has been argued that this discrepancy can cause confusion to the child, and ultimately impair adjustment (Bronfenbrenner \& Morris, 1998).

In an attempt to improve students' overall academic achievement and reduce the achievement gap between whites and children of color, state programs, including Florida, have poured a significant amount of funding into preschool programs. In 2004-2005, 800,000 children across the nation were enrolled in preschools at a cost of more than $\$ 2.8$ billion nationally (Barnett et al., 2005). Yet, even with the growth in preschool programs, funding and enrollment over the past 40 years (Pianta, 2005), the achievement gap persists (Norman et al., 2001). Since most teaching techniques reflect middle class families' life structure, researchers need to explore in more detail how literacy in middleclass families is different or similar to those of minority poor children (Vernon-Feagans et al., 2003).

There is an understanding that when it comes to literacy and book reading for children from low-income Latino homes, these experiences are harshly limited (VernonFeagans et al., 2003). A study conducted by Teale (1986) discussed, unlike the common belief that children from low-income Latino homes have little exposure to literacy, findings which suggested children were exposed to literacy throughout their day, but in

\footnotetext{
1 “[y]ou don't even know what you're scribbling."
} 
different ways. This included parents providing emotional support when it came to their schooling despite language barriers and even reading books to their children when it was available to them (Vernon-Feagans et al., 2003). Making assumptions without investigating these families will only create more harm and lead to more discrimination for children. The discontinuities Reese and Gallimore (2000) discussed in their article can diminish once parents adapt to change by changing their cultural model. What researchers and teachers alike most recognize is that language and literacy development occur in different ways and in different environmental settings than that of middle-class American children. As such, teachers should consider different approaches to teaching their culturally and linguistically diverse populations. Similarly, quality, as measured by white middle-class standards may not produce the same positive outcomes that have been demonstrated across white preschoolers.

\section{Current Study}

The current study includes participants of the Early Reading First- Learning Educational Approaches to Reading (ERF-LEARN) Project in Miami-Dade County. The Department of Education authorized the Early Reading First Program through the No Child Left Behind initiative (U.S. Department of Education, 2007). Funding was provided to those preschools who serve a high number of children who come from lowincome families between the ages of three and five. By providing funding to centers with children who come from low-income family, providers are able to impart age-appropriate developmental language, cognitive and literacy instruction to an educationally vulnerable population of children (U.S. Department of Education, 2008). ERF Programs were responsible for providing a rich, quality environment that supported early literacy in 
participating students. Instructional activities and materials had to come from evidencebased reading practices that would improve critical early literacy skills, including phonological awareness, print awareness, oral language, and alphabet knowledge (U.S. Department of Education, 2008). The program was also responsible in assessing and monitoring children's skills in order to track their progress and guide teacher instruction.

Significant work has been conducted on children who are impoverished, and has focused primarily on African Americans. However, the literature lacks evidence on the development of children from a Latino background (Burchinal et al., 2000; Garcia \& Jensen, 2009). The small amount of research that has focused on Latinos has tended to lump them in one single homogenous group, instead of focusing on the individual subcultures that come with the Latino community (Garcia \& Jensen, 2009). In order to provide these children with high quality day care that will cultivate their early literacy skills, researchers need to have a better understanding of the demographics and cultural contexts that surround these children. This means, understanding how the development of children's emergent literacy skills may differ from region to region, and how "white middle-class standards," of quality may not be culturally-sensitive or even applicable to these diverse populations (Brophy \& Statham, 1994; García Coll, 1990; García Coll et al., 1996; Johnson et al., 2003; Lamb, 1998). Although the focus of the present study is on stressing the importance of adhering to culturally sensitive standards with minority populations, these children still need to be ready to enter school with certain English language proficiency due to current state and national policy standards that are currently in place. Therefore, in the current study early literacy will be measured in English. 
The current study intends to establish some early work that looks at the language and literacy development of Latino preschoolers as a diverse community enrolled in preschools throughout Miami-Dade County. More specifically, the quality of the classroom environment, as measured by the ECERS-R, is expected to significantly moderate the relationship between region of origin and early preschool literacy skills in a population of Latino children. 


\section{CHAPTER III}

\section{Methodology}

\section{Participants}

Participants included 116 Latino children enrolled in one of four preschools in Miami-Dade County. The group represents a subset of children $(\mathrm{N}=306)$ who were enrolled in one of five preschools participating in an ERF-LEARN program, designed to improve the language and English literacy outcomes of low-income preschool children. The early learning centers participated in the ERF-LEARN program over two academic years. Centers were selected because of their ongoing service to low-income children receiving subsidies for childcare. Children were included in the current study if their parents identified them as Latino on a demographic survey. Because one of the participating centers did not have any Latino children enrolled in their center at the time of the study, that center was not included in the current analyses. Children were excluded if their parents did not fill out the question on their country of birth on the demographic survey. Forty-six percent of the participants were male and ranged in age from three to six years, with an average of 4.4 years $(S D=.57)$. For the $2006-2007$ school year, the centers had one classroom that participated in the program, yielding four classrooms for the current analyses. For Year Two of the study, centers had two classrooms participating, a veteran classroom from Year One of the study and an additional classroom that was added in Year Two. For the purposes of this study, only classrooms that were new to the program were included into the analyses. Classrooms that were "veterans" to the program for Year Two were not used in order to avoid confounding 
variables (e.g. history and maturation). This yielded eight different classrooms in all, two from each center, for both school years.

\section{Procedures}

For the curriculum, the participating classrooms in the ERF-LEARN program used the Literacy Express. The Literacy Express curriculum, designed for three- to fiveyear-old children, has met the What Works Clearinghouse (WWC) evidence standards. Given the research on over 900 children in preschools throughout California and Florida, the WWC considers the evidence supporting the use of the Literacy Express curriculum to be "moderate to large," in the areas of oral language development, print knowledge, and phonological processing (U.S. Department of Education, 2008). The curriculum is delivered by all participating teachers completely in English and was implemented throughout the academic year.

Parents of all the participating ERF-LEARN students were asked to complete a demographic survey at the beginning of the academic year (August-September). Questions that were used for this study included child's and parent's race/ethnicity, and mother's country of birth. The sample size of the current study did not allow for an examination of country of origin. From the information collected from the parents, participating children were then categorized into a variable called, Region of Origin. Each region was determined by geographical and cultural similarities (Karl, 1995; Booth, 1991; Reese \& Gallimore, 2000). This yielded three levels of the variable Region of Origin: (1) Mexico and Central America that included students from Mexico ( $n=14)$, El Salvador $(n=1)$, Honduras $(n=11)$, Guatemala $(n=2)$, and Nicaragua $(n=6) ;(2)$ South America that included students from Peru $(n=3)$, Columbia $(n=6)$, Venezuela $(n=3)$, and 
Argentina ( $n=5)$; and (3) Latino Caribbean that included students from Cuba $(n=44)$, Dominican Republic $(n=8)$, and Puerto Rico $(n=13)$. Although children from Puerto Rico are considered U.S. citizens, it is important to note that they were not born in the U.S. mainland and special attention should be given to the cultural and geographical differences of those students born in the mainland and those who were born in Puerto Rico (Han, 2006). Despite studies treating Mexico and Central America as two different regions, this study categorized them as one region due to their economic and political conditions that led the population to migrate (Bronfman, 1998) and to their similar cultural model of literacy development (Reese \& Gallimore, 2000). Student information is listed by center in Table 1.

Table 1

Descriptive Statistics: Means and Standard Deviations of ECERS-R and TOPEL Performance by Childcare Center

Center $A \quad$ Center $B \quad$ Center $C \quad$ Center $D$

Child characteristics

Region of Origin

South America (\%)

Central America and Mexico (\%) 14

Latino Caribbean (\%)

66

20

24

4

18

$14 \quad 35$

56

0

Gender

Male (\%)

34

59

40

Female (\%)

66

41

60

Age $M(S D)$

4.31

4.26

4.44

4.64

(.58)

(.45)

(.51)

All students included in this study were administered a battery of early literacy assessments, which included the Test of Preschool Early Literacy (TOPEL). As a 
requirement of the ERF-LEARN program, a team of assessors conducted evaluations of children's literacy skills at two time points during both years of the program. The students were assessed on the TOPEL in both the fall and spring of both Year One and Year Two. For the purpose of the current study, only posttest scores were used in the analyses because this gives an indication of children's literacy levels as they enter kindergarten. Post-test assessments of the TOPEL were collected in April-May of the academic school year. Data was limited as to how many children were classified as English Language Learners. Since curriculum was based on English literacy skills, the TOPEL was conducted in English.

Assessments on environmental quality were also conducted. The ECERS-R scores were collected on participating centers at two time points during both academic years. Pretest scores were collected during the first half of the year and posttest scores were collected during the second half of the year. Pre-test scores of the ECERS-R were used in the current analyses. Assessments ECERS-R were conducted in AugustSeptember. Pre-test scores provided a more accurate measure of the environment before the intervention made direct modifications to the environment. A reliable assessor observed the classrooms of interest and assigned a rating to each subscale of interest. Measures

Early Childhood Environment Rating Scale-Revised Edition (ECERS-R; Harmset al., 2005). The ECERS-R is an observational measure that examines the classroom environment of children from two to five years of age. It evaluates the environment from structural perspectives, such as program structure, and process perspectives, such as interactions. The ECERS-R contains 97 Likert scale items that together comprise of 
seven subscales. The subscales include space and furnishings, personal care routines, language and reasoning, activities, interaction, program structure, and parents and staff. The ECERS-R provides evaluators with seven different scores for each different subscale and an overall average score, which are rated on a 7 point Likert scale ranging from 1-7, having $1=$ inadequate, $3=$ minimal, $5=$ good, and $7=$ excellent care. For the ECERS-R overall scores, 1.0 to 2.9 indicates poor quality care, 3.0 to 4.9 mediocre care, and 5.0 to 7.0 good quality care. Each subscale does not have the same number of items, but the overall average of the ECERS-R is derived from averaging the overall averages of each individual subscale. For the ERF-LEARN program, data were not collected on the parents and staff subscale. Since data were not collected on the parents and staff subscale, the total scores for the ECERS-R were calculated by adding all the subscale scores and dividing by six and not seven as it is typically scored on the ECERS-R.

Inter-rater reliability on the ECERS-R has a Pearson product coefficient of .92 and a Spearman rank order of .87 (Harms et al, 1998). The ECERS-R also had an internal consistency of .92 and inter-rater intra-class correlations of .71 to .88 (Harms et al., 1998). The inter-rater internal consistencies for each subscale were .76 for space and furnishings, .72 for personal care routines, .83 for language-reasoning, .88 for activities, .86 for interaction, and .77 for program structure (Harms et al., 1998).

Test of Preschool Early Literacy (TOPEL; Lonigan et al., 2007). The purpose of the TOPEL is to assess the early literacy skills of children three to five years of age and provides a composite score that is formed by combining all the scores of three subscales. Participants are instructed to respond to items that reflect the following three subscales: print knowledge, definitional vocabulary, and phonological awareness. The print 
knowledge subscale consists of 36 items that measure the child's ability to recognize different aspects of print such as letters and written words. The child is asked to point, name, and say the sound of some specific letters as well as to identify sounds that are related to the specific letter. The definitional vocabulary subscale consists of 35 items that measure the child's ability in oral and definitional vocabulary by assessing surface and deep vocabulary knowledge. The child is shown a picture and is asked to identify it and describe important features and attributes, going into deep vocabulary knowledge. The third subscale focuses on phonological awareness and is composed of a 27 -item scale measuring elision and blending. Elision skills are tested by asking the child to say a word and then after dropping out specific sounds they are asked to say what new word has been created. Blending ability skills are measured by listening to separate sounds and then combining them to form a new word. The average scores of the three subscales provide the assessor with an Early Literacy Index (ELI). The standard score means for the Hispanic American population for the composite score of the ELI is 102 with a standard deviation of 16. This composite score is considered representative of the child's emergent literacy skills. The TOPEL was normed with 842 children residing in 12 states and provides assessors with an average standard score of 100 and a standard deviation of 15. Internal consistency reliability of the TOPEL early literacy index is .96 (Lonigan et al., 2007). The TOPEL is usually used to identify children who might be having trouble learning to read and write, as well to track their progress in their early literacy skills and as well to measure early literacy skills in research studies. 


\section{CHAPTER IV}

\section{Results}

Preliminary statistics indicated that TOPEL ELI scores ranged from 51-128, with a mean score of $85.6(S D=18.2)$, which is below the standardized norm for the Latino American population. Participating classrooms scores on the ECERS-R ranged from 3.43-5.72, with a mean of $5.05(S D=.68)$, indicative of good quality care.

\section{Research Question 1}

A linear regression was conducted to examine the effect of the childcare classroom environmental quality on children's early literacy outcomes on the posttest score of the TOPEL ELI (see Figure 1 in Chapter 1) yielding the following equation:

$$
Y_{E L}=a+\beta_{1} \text { Quality }+e
$$

where $\boldsymbol{Y}_{\boldsymbol{E} \boldsymbol{l}}$ signifies early literacy outcomes and Quality signifies the measure of environmental quality by ECERS-R standards. Results of the regression $\left(R^{2}=.03\right.$, $F(1,115)=3.6, p>.05)$ indicated that the ECERS-R total score was not a significant predictor of the TOPEL ELI at the end of the pre-k year $(\beta=.18, \mathrm{~B}=4.69, p>.05)$.

Table 2

Regression Results for the Relationship between Childcare Quality and Early Literacy Scores

\begin{tabular}{|c|c|c|c|c|}
\hline \multirow[b]{2}{*}{ Variable } & \multicolumn{4}{|c|}{ TOPEL ELI } \\
\hline & $B$ & $\begin{array}{c}S E \\
B\end{array}$ & $\beta$ & $95 \% C I$ \\
\hline Intercept (constant) & 85.60 & 1.67 & & 82.28 to 88.91 \\
\hline ECERS-R & 4.70 & 2.47 & .175 & -.208 to 9.60 \\
\hline$R^{2}$ & & .031 & & \\
\hline$F$ for change in $R^{2}$ & & .360 & & \\
\hline
\end{tabular}

More specifically, childcare classroom environmental quality as measured by the

ECERS-R did not account for a significant amount of the variance in children's early 
literacy outcomes as measured by the TOPEL. Table 2 presents the coefficients for this model.

\section{Research Question 2}

A second hierarchical multiple linear regression was computed to determine whether region of origin significantly moderated the effect of childcare classroom environmental quality on early literacy outcomes in the current sample (see Figure 2 from Chapter 1). The focal independent variable and dependent variable remained the same as in question one. For this analysis, two dummy variables were created to test for an interaction effect between classroom environmental quality and region of origin and its effects on the dependent variable, the TOPEL ELI. The current study examined Region of Origin as three distinct levels, Mexico and Central America, South America, and Latino Caribbean. All were converted into dummy variables. The first dummy variable, $D_{M C}$, included all children who were identified as coming from Mexico and Central America, and were assigned a 1, while all others were assigned a 0 . The second dummy variable, $D_{S A}$, included all children who came from South America, and all of those children were assigned a 1 and everyone else was assigned a 0 . Latino Caribbean was the designated reference group and had 0 s for both variables.

The regression equation included a product term, which tested the interaction effect, that multiplied classroom environmental quality times the dummy variables for region, and then inserted this product term and its component parts as predictors (Jaccard, 2001), thus yielding:

$$
\begin{aligned}
Y_{E L}= & a+\beta_{1} \text { Quality }+\beta_{2} D_{M C}+\beta_{3} D_{S A}+\beta_{4} \text { Quality }_{-} D_{M C} \\
& +\beta_{5} \text { Quality_D } D_{S A}+e
\end{aligned}
$$


For the first step of the model, the pre-test scores of the ECERS-R were entered. In the second step of the model, dummy variables $D_{M C}$ and $D_{S A}$ were entered. Interaction effects were entered in the third step of the model. Results of the model $(\beta=.00, \mathrm{~B}=-$ $11.51, p<.05)$ indicate a significant interaction effect, such that classroom environmental quality explained a significant proportion of variance in early literacy skills as a function of region of origin $\left(R^{2}=.15, F(5,115)=3.86, p<.05\right)$. Children from Mexico and Central America scored significantly lower on the TOPEL. There is a significant group difference in means between children from Mexico and Central America and the Latino Caribbean on their early skills outcome.

Table 3

Coefficients for Quantitative and Qualitative Predictors: Two-Way Interactions

\begin{tabular}{|c|c|c|c|c|c|c|c|c|c|}
\hline \multirow{2}{*}{$\frac{\text { TOPEL ELI }}{\text { Variable }}$} & \multicolumn{3}{|c|}{ Model 1} & \multicolumn{3}{|c|}{ Model 2} & \multicolumn{3}{|c|}{ Model 3} \\
\hline & $B$ & $\begin{array}{c}S E \\
B \\
\end{array}$ & $\beta$ & $B$ & $\begin{array}{c}S E \\
B \\
\end{array}$ & $\beta$ & $B$ & $\begin{array}{c}S E \\
B \\
\end{array}$ & $\beta$ \\
\hline Intercept (constant) & 85.60 & 1.67 & & & & & 89.56 & 2.23 & \\
\hline $\begin{array}{l}\text { ECERS- } \mathrm{R}_{\mathrm{C}} \\
\text { Region of Origin }\end{array}$ & 4.70 & 2.47 & .175 & & & & 6.92 & 4.03 & .258 \\
\hline $\begin{array}{l}\text { South America } \\
\left(D_{\mathrm{SA}}\right)\end{array}$ & & & & $-9.59^{*}$ & 4.52 & -.199 & -8.29 & 4.50 & -.172 \\
\hline $\begin{array}{l}\text { Mexico and } \\
\text { Central America } \\
\left(\mathrm{D}_{\mathrm{MC}}\right)\end{array}$ & & & & $11.23^{* *}$ & 3.94 & -.274 & -12.29 & 3.93 & -.300 \\
\hline $\begin{array}{l}\text { ECERS- } \mathrm{R}_{\mathrm{C} \_} \text {Region } \\
\text { of Origin }\end{array}$ & & & & & & & & & \\
\hline ECERS-R $\mathrm{C}_{-} \mathrm{D}_{\mathrm{SA}}$ & & & & & & & .003 & 6.31 & -.262 \\
\hline ECERS-R $\mathrm{C}_{-} \mathrm{D}_{\mathrm{MC}}$ & & & & & & & $11.51^{*}$ & 5.67 & .000 \\
\hline$F$ value & & 3.60 & & & $4.57^{* *}$ & & & $3.86^{* *}$ & \\
\hline$R^{2}$ & & .031 & & & .109 & & & .149 & \\
\hline$F$ for change in $R^{2}$ & & 3.60 & & & $4.93^{* *}$ & & & 2.59 & \\
\hline
\end{tabular}

Note. ECERS-R total scores were mean centered to avoid problems with multicollinearity. $B=$ unstandardized regression coefficient; $\beta=$ standardized regression coefficient; $S E=$ standard error; TOPEL ELI $=$ Test of Preschool Early Literacy Index; ECERS-R= Early Childhood Environmental Scale-Revised. ${ }^{*} p<.05 .{ }^{* *} p<.01$.

There is a 11.51 mean unit difference on the TOPEL ELI when the ECERS-R score is at its mean (Table 3). Figure 3 demonstrates a graphical presentation of the interaction effect. Results indicate a positive relationship between quality and literacy outcomes for 
children from the Latino Caribbean. Children in high quality classroom environments, as indicated by the ECERS-R, result in better early literacy skills before entry to Kindergarten. However, for Mexican and Central American children, a high quality classroom was a negative predictor later literacy outcome. The effects for Latino Caribbean and Mexican and Central American children were significant. South American children also demonstrated poorer scores of early literacy in classrooms receiving high scores on the ECERS-R, although this effect was not significant. It is important to note that this does not specifically mean that high quality as indicated by the ECERS-R means that children will have lower outcomes. Instead, this suggests there may be a disconnect between "quality," as measured by White-European standards and "quality," that is required for children from a different regions of Latino origin.

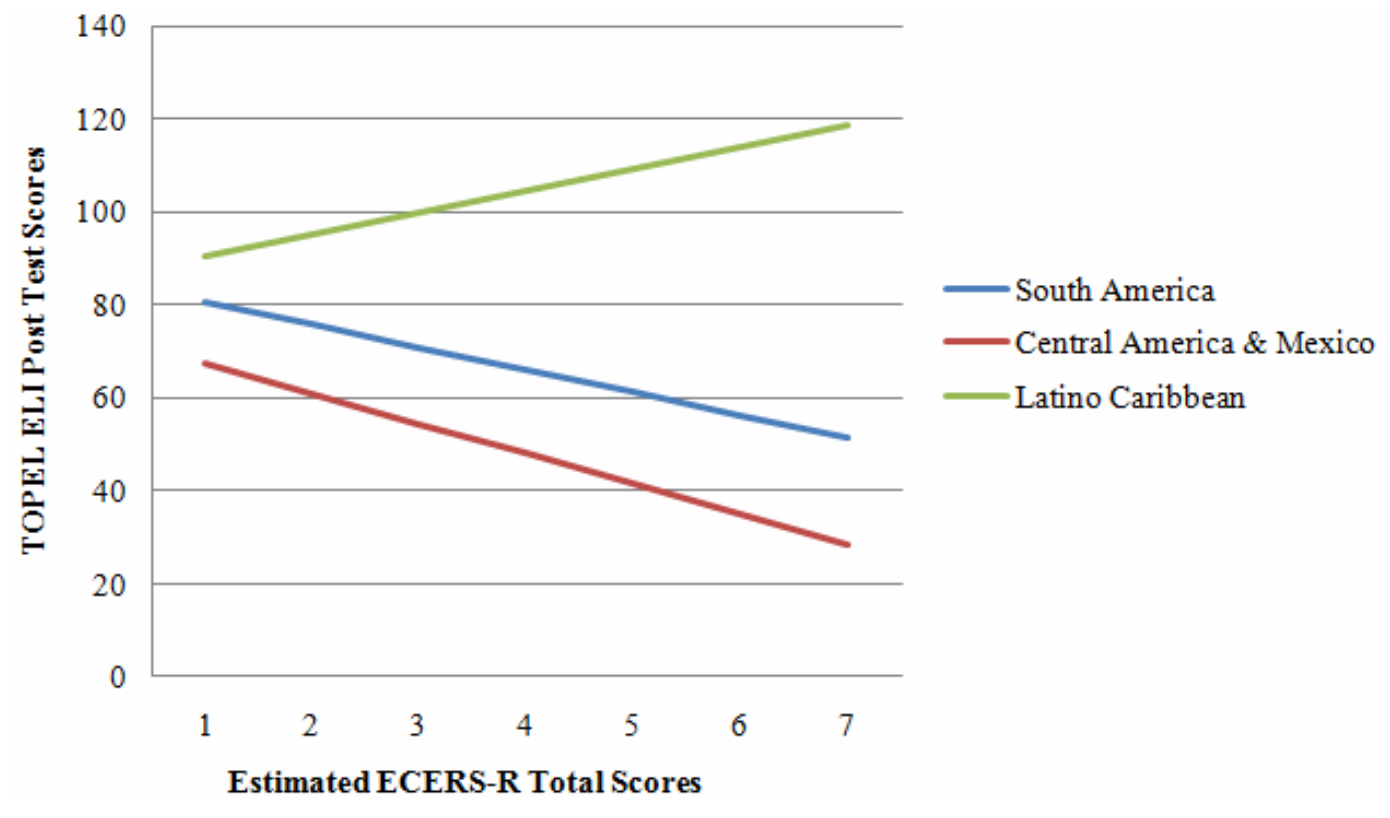

Figure 3. Regression Lines Predicting Early Literacy Outcomes of TOPEL ELI Post Test Scores from Childcare Classroom Environmental Quality of ECERS-R Total Score as a Function of Child's Region of Origin. 
Although initial analyses demonstrated that quality was not an overall predictor of language and literacy in Latino preschoolers, secondary analyses demonstrated that region of origin significantly moderated the effect of environmental quality on the early literacy development of Latino preschoolers. To test for program intervention effects, pretest scores on the TOPEL ELI were explored by rerunning the regressions. 


\section{CHAPTER V}

\section{Discussion}

Results of the current study suggest that the ECERS-R is a nonequivalent measure across different ethnic groups, in this case a group with Latino origins. Although the ECERS-R was a significant predictor of outcome for children of Latino Caribbean descent, the same was not true for children from Mexico and Central America and South America. In fact, it appears that children from South America and particularly, Mexico and Central America are doing more poorly in classrooms rated highly in classroom quality. This counterintuitive finding, suggests that the definition of quality may be different not only for culturally diverse groups, but for children from regionally diverse groups. The ECERS-R did account for early literacy outcomes, but this depends on where children come from. Given this inconsistency with which the ECERS-R was able to predict early literacy outcomes, it may be that other measures of quality should be considered when studying Latino children.

Quality is broadly defined as an early learning environment that enhances positive development in young children (Dickinson \& Sprague, 2003). The ECERS-R in this case might not be capturing this with this specific group of Latino children. Initial analyses were consistent with Mashburn and colleagues (2008) who found that the ECERS-R was not a good predictor of preschool outcome. While results for model 1 tell us something about Latinos as a whole, research indicates (Johnson et al, 2003; Garcia \& Jensen, 2009) that testing these research questions with Latinos, as a group, rather than examining regional differences may be problematic. As Garcia and Jensen (2009) suggest, Latino children's developmental and early academic outcomes should be evaluated as a 
heterogeneous group, rather than the homogenous group that has historically been evaluated.

Results also expand on Mashburn and colleagues (2008) study, which used the ECERS-R to test the overall quality of different childcare centers in their study. Their sample consisted of 2,439 children, where only $17 \%$ were classified as Latino. Their results showed that the ECERS-R had no significant association to the overall quality in the childcare center. Similarly, Burchinal and Cryer (2003) examined the role of quality in ethnically and culturally diverse backgrounds. Their study was highly inclusive of African Americans and only focused on a very small number of Latino children, making it difficult to generalize the findings to Latino populations.

Results of model 2 (see Figure 2 in Chapter 1) indicate that region of origin significantly moderates the effect of classroom environmental quality on the early literacy development of Latino preschoolers. When individual region of origin was examined as a potential moderator, analyses revealed that quality was positively related to language and literacy for Latino Caribbean, but not for children from Mexico and Central America or South America.

Findings for the second model partially support findings of other studies such as the NICHD Early Child care Research Network and Duncan (2003) and Burchinal and colleagues (2000). The NICHD Early Childcare Research Network and Duncan (2003) findings suggested that quality of classroom environment was important in enhancing the language development of children who come from impoverished families. Similarly, Burchinal and colleagues (2000) indicated in their results that there was a significant relationship between quality of classroom environment and early literacy skills in the first 
three years of life. Although these studies focused on impoverished families and highrisk children, they are limited in their ability to provide a true picture of what high quality education should be for these children.

The overall findings of the study support what others (e.g., Garcia \& Jensen, 2009) in the literature have been advocating. There is a need in research to oversample Latino children in order to be able to compare them to other children from different countries of origin outside of the United States. This will result in a more detailed picture of how they are performing in school. A possible explanation why children from Central America and Mexico are not performing well with respect to literacy outcomes despite attending childcare centers that are rated high in quality may be due to socioeconomic status, social class, culture, and/or maternal education. Cohen (2009) noted that socioeconomic status and social class have important implications for the development, well-being, and physical health of people. As noted, literacy practices can differ by region of origin (Gillanders \& Jiménez, 2004; Vernon-Feagans et al., 2003; Reese and Gallimore, 2000). Latino children have the added burden of negotiating different sets of literacy rules in the home and school (Vernon-Feagans et al., 2003; Jonson et al., 2003). This disconnect can be problematic for children's learning since discrepancies between the home and school can cause confusion to the child that can impair adjustment to the environments (Bronfenbrenner \& Morris, 1998).

\section{Implications for Future Research}

For early childhood researchers and practitioners, these findings have important implications because it can serve as a preliminary guide for future research directions when studying children from Latin America. The results of the present study suggest that 
although ecological surroundings are important predictors of children's learning (Han, 2006), this may not be apparent when grouping children from different ethnic regions or nationalities. The finding that children from the Latino Caribbean perform similar to white, middle class children, than the other Latino groups may be due to the socioeconomic status of their region and the social support provided to them in Southeast Florida. This is because children who come from Cuba, for example, have the advantage of an agreement between the U.S. and their country (Perez, 2004). In 1994, President Clinton enacted the Wet-Foot/Dry-Foot Policy, where Cuban immigrants upon touching dry land in the U.S. would be automatically granted asylum (Perez, 2004). Aside from Puerto Rico, which is a U.S. territory and are U.S. citizens, Cuba is the only known country whose immigrants hold this right. These results also have implications for policy makers to ensure that if classroom quality is going to be a good indicator on children's outcomes, then quality may need to be redefined based on the Latino population.

\section{Limitations and Future Research Directions}

This research provided initial support that: (1) classroom environmental "quality" may have different definitions for different populations and (2) individual differences and understanding of culturally and linguistically diverse populations needs to be further emphasized in the early childhood classroom. However, the current study had some limitations. First, the data collection was only with children who attended centers that were participating in the funded ERF program. The children participating in ERF received a specified English language curriculum that not all children in Southeast Florida receive. Future studies should consist of a larger sample size that includes 
students throughout all Southeast Florida who might and might not be participating in grant funded, intervention programs.

Second, the current study did not look at the psychometric properties of either the ECERS-R or the TOPEL in relation to this population. The ECERS-R serves multiple purposes, one of them assessing quality, but it also helps in research, state regulations, and consultations for centers (Cassidy et al., 2005). With such precedence the ECERS-R has, there have been a few studies that have looked at the psychometric properties of the ECERS-R. Psychometric properties and measurement errors are known to have an important role in interaction effects (Jaccard, 2001). Therefore, future studies should examine the psychometric properties of the ECERS-R more in depth.

Third, the current study did not examine other family demographic variables that may explain why children from Central America and Mexico were performing low on the TOPEL ELI despite attending centers that rated high on quality according to the ECERS$\mathrm{R}$ total score. Future research should control or study maternal education level and parents years of residency in the United States (Han, 2006). Controlling or adding these variables to the study may paint a clearer picture of why children from Central America and Mexico are not performing as well as their peers despite attending centers that are rated high in quality and will allow researchers to look more closely at children's ecological surroundings outside of the classroom.

\section{Conclusion}

In summary, these findings suggest that children from a Latin American background should be studied not as a homogenous group, but as a heterogeneous one. This will allow for results that are more valid when studying classroom environmental 
quality and English literacy outcomes. Despite the limitations of the present study, this research adds to the literature of quality and English literacy and its relation to children who come from a diverse background, especially the Latino population.

These results provide support for the implementation of programs that adhere and reach out to diverse populations. This study's findings support the need for more research focusing on observing Latino children's actual experiences in their early classroom environments and instead of looking at a global aspect of quality, focusing on specific factors that might go beyond quality in the classroom. 


\section{REFERENCES}

Acevedo-Garcia, D., Soobader, J., \& Berkman, L.F. (2007). Low birthweight among US Hispanic/Latino subgroups: The effect of maternal foreign-born status and education. Social Science \& Medicine, 65, 2503-2516.

Barnett, W.S., Hustedt, J.T., Robin, K.B., \& Schulman, K.L. (2005). The state of preschool: 2005 state preschool yearbook. New Brunswick, NJ: The National Institute for Early Education Research.

Booth, J.A. (1991). Socioeconomic and political roots of national revolts in central America. Latin American Research Review, 26, 1, 33-73.

Bronfenbrenner, U., \& Evans, G. (2000). Developmental science in the $21^{\text {st }}$ century: Emerging questions, theoretical models, research designs and empirical findings. Social Development, 9, 1, 115-125.

Bronfenbrenner, U., \& Morris, P.A. (1998). The bioecological model of human development. In W. Damon (Series Ed.) \& R.M. Lerner (Vol. Ed.), Handbook of Child Psychology: Vol 1. Theoretical models of human development (pp. 793-828). New York: Wiley.

Bronfman, M. (1998). Mexico and Central America. International Migration, 36, 4, 609642.

Bophy, J., \& Statham, J. (1994). Measure for measure: Values, quality and evaluation in valuing quality in early childhood services. In P. Moss and A. Pence (Eds). Valuing Quality in early Childhood Services. London: Paul Chapman.

Burchinal, M.R. \& Cryer, D. (2003). Diversity, child care quality, and developmental outcomes. Early Childhood Research Quarterly, 18, 401-426.

Burchinal, M.R., Roberts, J.E., Riggins, R., Zeisel. S.A., Neebe, E., Bryant, D. (2000). Relating quality of center-based child care to early cognitive and language development longitudinally. Child Development, 71, 2, 339-357.

Cassidy, D.J., Hestenes, L.L., Hegde, A., Hestenes, S., Mims, S. (2005). Measurement of quality in preschool child care classrooms: An exploratory and confirmatory factor analysis of the early childhood environment rating scale-revised. Early Childhood Research Quarterly, 20, 345-360.

Cohen, A.B. (2009). Many forms of culture. American Psychologist, 64, 3, 194-204.

Cryer, D. (1999). Defining and assessing early childhood program quality. Annals of the American Academy of Political and Social Science, 563, 39-55. 
Dickinson, D.K., \& Sprague, K.E. (2003). The nature and impact of early child care environments on the language and early literacy development of children from low-income families. In Neuman, S.B., Dickinson, D.K. (Eds.), Handbook of Early Literacy Research Volume 1. New York: The Guilford Press.

Flores, E., Cicchetti, D., \& Rogosch, F.A. (2005). Predictors of resilience in maltreated and nonmaltreated Latino children. Developmental Psychology, 41, 2, 238-351.

Garcia, E. \& Jensen, Bryant. (2009). Early education opportunities for children of Hispanic origins. Social Policy Report, XXIII, II, 3-19.

García Coll, C., Lamberty, G., Jenkins, R., McAdoo, H.P., Crnic, K., Wasik, B.H., \& Vazquez García, H. (1996). An integrative model for the study of developmental competencies in minority children. Child Development, 67, 5, 1891-1941.

García Coll, C. (1990). Developmental outcome of minority infants: A process-oriented look into our beginnings. Child Development, 61, 2, 270-289.

Gillanders, C., \& Jiménez, R. (2004). Reaching for success: A close-up of Mexican immigrant parents in the USA who foster literacy success for their kindergarten children. Journal of Early Childhood Literacy, 4, 243-269.

Harms, T., Clifford, R.M., \& Cryer, D. (1998). Early Childhood Environment Rating Scale-Revised Edition. NY: Teachers College Press.

Harms, T., \& Clifford, R.M. (1980). The early Childhood Environment Rating Scale. New York, NY: Teachers College Press.

Han, W.J. (2008). The academic trajectories of children of immigrants and their school environments. Developmental Psychology, 44, 6, 1572-1590.

Han, W.J. (2006). Academic achievements of children in immigrant families. Educational Research and Review, 1, 8, 286-318.

Hoffman, L., \& Sable, J. (2006). Public elementary and secondary students, staff, schools, and school districts: School year 2003-04 (NCES 2006-307). U.S. Department of Education. Washington, DC: National Center for Education Statistics.

Jaccard, J. (2001). Interaction Effects in Logistic Regression. Sage University Papers Series on Quantitative Applications in the Social Sciences, 07-135. Thousand Oaks, CA: Sage. 
Johnson, D.J., Jaeger, E., Randolph, S.M., Cauce, A.M., Ward, J., \& NICHD Early Child Care Research Network. (2003). Studying the effects of early child care experiences on the development of children of color in the United States: Toward a more inclusive research agenda. Child Development, 74, 5, 1227-1244.

Karl, T.L. (1995). The hybrid regimes of Central America. Journal of Democracy, 6, 3, $72-86$.

Lamb, M.E. (1998). Nonparental child care: Context, quality, correlates, and consequences. In W. Damon (General Ed.) \& I.E. Siegel \& A. Renninger (Vol. Eds.) Handbook of child psychology: Child psychology in practice. New York: Wiley.

Lonigan, C.J., Wagner, R.K., Torgesen, J.K., \& Rashotte, C.A. (2007). Test of Preschool Early Literacy. Austin, TX: PRO-ED.

Magnuson, K.A., Meyers, M.K., Ruhm, C.J., \& Waldfogel, J. (2004). Inequality in preschool education and school readiness. American Educational Research Journal, 41, 1, 115-157.

Mashburn, A.J., Pianta, R.C., Hamre, B.K., Downer, J.T., Barbarin, O.A., Bryant, D., Burchinal, M., ... Howes, C. (2008). Measures of classroom quality in prekindergarten and children's development of academic, language, and social skills. Child Development, 79, 3, 732-749.

Meléndez, L. (2005). Parental beliefs and practices around early self-regulation: The impact of culture and immigration. Infants \& Young Children, 18, 2, 136-146.

National Center for Education Statistics. (2005). Child care arrangements of 3- to 5year-old children who are not yet in kindergarten, buy age and racelethnicity: 2005. Retrieved September 10, 2009, from http://nces.ed.gov/fastfacts/display.asp?id=4.

National Institute of Child Health and Human Development Early Child Care Research Network. (2005). A New Guide for Evaluating Child Care Quality. In NICHD (Eds.), Child Care and Child Development. New York: The Guilford Press.

National Institute of Child Health and Human Development Early Child Care Research Network, \& Duncan, G.J. (2003). Modeling the impacts of child care quality on children's preschool cognitive development. Child Development, 74, 5, 14541475 . 
Norman, O., Ault, C.R., Bentz, B., \& Meskimen, L. (2001). The black-white "achievement gap" as perennial challenge of urban science education: A sociocultural and historical overview with implications for research and science. Journal of Research in Science Teaching, 38, 10, 1101-1114.

Peisner-Feinberg, E.S., Burchinal, M.R., Clifford, R.M., Culkin, M.L., Howes, C., Kagan, S.L., \& Yazejian, N. (2001). The relation of preschool child-care quality to children's cognitive and social development trajectories through second grade. Child Development, 72, 5, 1534-1553.

Peisner-Feinberg, E.S., \& Burchinal, M.R. (1997). Relations between preschool children's child care experiences and concurrent development: The cost, quality, and outcomes study. Merrill-Palmer Quarterly, 43, 451-477.

Perez, A.J. (2004). Wet foot, dry foot, no foot: The recurring controversy between Cubans, Haitians, and the United States immigration policy. Nova Law Review, 28, 2, 437-466.

Perlman, M., Zelman, G.L., Le, V. (2004). Examining the psychometric properties of the Early Childhood Environment Rating Scale-Revised (ECERS-R). Early Childhood Research Quarterly, 19, 398-412.

Phillips, D.A., \& Howes, C., (1987). Indicators of quality in child care. Review of Research. In D.A. Phillips (Ed.) Quality in child care: What does the research tell us? Research Monograph of the National Association for the Education of Young Children: Vol. 1. Washington, DC: NAEYC.

Pianta, R. C. (2005). A new elementary school for American children. SRCD Social Policy Report 19(3), 4-5.

Proctor, C.P., Carlo, M., August, D., \& Snow, C. (2005). Native Spanish-speaking children reading in English: Toward a model of comprehension. Journal of Educational Psychology, 97, 2, 246-256.

Proctor, B.D., \& Dalaker, J. (2003). Poverty in the United States: 2002 (Current Population Reports, P60-222). Washington, DC: US Census Bureau.

Reese, L., \& Gallimore, R. (2000). Immigrant Latino's cultural model of literacy development: An evolving perspective on home-school discontinuities. American Journal of Education, 108, 2, 103-134.

Roskos, K., Neuman, S.B. (2003). Environment and its influence for early literacy teaching and learning. In Neuman, S.B., Dickinson, D.K. (Eds.), Handbook of Early Literacy Research Volume 1. New York: The Guilford Press. 
Super, C.M., \& Harkness, S. (1986). The developmental niche: A conceptualization at the interface of child and culture. International Journal of Behavioral Development, 9, 545-569.

Takanishi, R. (2004). Leveling the playing field: Supporting immigrant children from birth to eight. The Future of Children, 14, 2, 61-790.

Teale, W. (1986). Home background and young children's literacy development. In W. Teale \& E. Sulzby (Eds.), Emergent literacy: Writing and research (pp. 173206). Norwood, NJ: Ablex.

Thelen, E., \& Smith, L.B. (1998). Dynamic system-theories. In W. Damon (Series Ed.) \& R.M. Lerner (Vol. Ed.), Handbook of Child Psychology: Vol 1. Theoretical models of human development (pp. 258-312). New York: Wiley.

U. S. Census Bureau. (2007). State \& county Quick facts: Allegany County, N.Y.

Retrieved April 6, 2009, from

http://factfinder.census.gov/servlet/ACSSAFFFacts?_event=Search\&_lang=en \&_Sse $=$ on\&geo_id $=04000$ US $12 \&$ \&tate $=04000$ US 12

U. S. Department of Education. (2008). Preschool: First findings from the third follow-up of the early childhood longitudinal study, birth cohort (ecls-b). (NCES No. 2008025). Retrieved September 8, 2009, from http://nces.ed.gov/pubsearch/ pubsinfo.asp?pubid=2008025.

U.S. Department of Education, National Center for Education Statistics. (2008). Digest of Education Statistics, 2007. Retrieved September 8, 2009 from http://nces.ed.gov/fastfacts/display.asp?id=4

U.S. Department of Education (2007). National Evaluation of Early Reading First. Washington, DC: Institute of Education Sciences. Retrieved April 6, 2009 from http://www.nova.edu/library/dils/lessons/apa/index.htm\#government

Vandell, D., \& Wolfe, B. (2000). Child care quality: Does it matter and does it need to improve? (Special Report No. 78). Madison, WI: Institute for Research on Poverty, University of Wisconsin-Madison.

Vernon-Feagans, L., Hurley, M.M., Yont, K.M., Wamboldt, P.M., \& Kolak, A. (2007). Quality of childcare and otitis media: Relationship to children's language during naturalistic interactions at 18,24, and 36 months. Journal of Applied Developmental Psychology, 28, 115-133. 
Vernon-Feagans, L., Scheffner Hammer, C., Miccio, A., \& Manlove, E. (2003). Early language and literacy skills in low-income African American and Hispanic children. In Neuman, S.B. \& Dickinson, D.K. (Eds.), Handbook of Early Literacy Research Volume 1. New York: The Guilford Press.

Votruba-Drzal, E., Coley, R.L., \& Chase-Lansdale, L. (2004). Child care and lowincome children's development: Direct and moderated effects. Child Development, 75, 1, 296-312.

Whitehurst, G.J., Lonigan, C.J. (2003). Emergent literacy: Development from prereaders to readers. In Neuman, S.B. \& Dickinson, D.K. (Eds.), Handbook of Early Literacy Research Volume 1. New York: The Guilford Press. 